\title{
A case of respiratory sinus arrhythmia and vasovagal attacks: use of cosinor analysis for diagnosis and for monitoring treatment
}

\author{
G R PAI, JOHN M RAWLES \\ From the Department of Medicine, University of Aberdeen
}

SUMMARY An 18 year old girl presented with frequent vasovagal attacks and sinus arrhythmia. The amplitude of respiratory sinus arrhythmia assessed by cosinor analysis was $20 \%$; the predicted value for a normal girl of this age is $4 \%$ and the $95 \%$ confidence interval is $0-8 \%$. Treatment with propantheline, in a dose sufficient to reduce the amplitude of sinus arrhythmia to normal, abolished her symptoms.

Increased vagal tone is a recognised cause of syncope and near syncope ${ }^{1}$; it occurs more commonly in young people or in trained athletes. ${ }^{23}$ The diagnosis of this condition usually rests on the clinical presentation together with evidence of vagotonia on the electrocardiogram, and it depends on electrophysiological studies for confirmation. ${ }^{45} \mathrm{We}$ report a patient in whom vagal tone was increased and in whom the diagnosis was made by quantifying the amplitude of respiratory sinus arrhythmia on a three minute electrocardiogram by means of cosinor analysis by microcomputer.

\section{Patient and methods}

\section{ELECTROCARDIOGRAM RECORDING}

In order to minimise voluntary hyperventilation, the subject was not told that her respiration was to be observed. A three minute electrocardiogram was recorded at a paper speed of $50 \mathrm{~mm} / \mathrm{s}$ from standard lead I with the patient supine during normal spontaneous respiration. Movement of the chest was observed throughout the recording and the event marker was pressed in the pause at the end of each expiration.

We measured the P-P intervals and their relation to end expiratory points using a digitising pad and microcomputer with a resolution of $0.1 \mathrm{~mm}$; the results were stored on disc.

No reprints will be available.

Accepted for publication 20 January 1987

\section{COSINOR ANALYSIS}

Cosinor analysis was used to demonstrate the respiratory variation of heart rate. The best fit of a cosine function curve to the cyclical variation of P-P intervals was found by multiple regression analysis. The duration of each respiratory cycle was taken as $360^{\circ}$, with both 0 and 360 signifying end expiratory points. The timing of each $\mathbf{P}$ wave in the respiratory cycle in which it occurred was expressed as an angular measure $(t)$. The duration of the associated P-P interval was expressed as a percentage of the mean P-P interval for the whole three minute sequence and this was regressed against $\cos (t)$ and $\sin (t)$ to give the amplitude, phase angle, and statistical significance of respiratory variation of the $\mathrm{P}-\mathrm{P}$ interval, forced into the form of a cosine function curve. Cosinor analysis was described by Halberg $e t \mathrm{al}^{6}$ and its application to electrocardiogram intervals will be reported by Pai $e t$ $a .^{7}$

\section{Example}

An 18 year old student radiographer presented in March 1985 with a five month history of blackouts which had latterly been occurring three or four times a day. They invariably occurred when she was standing, and from her description there was no reason to think that the blackouts were other than vasovagal attacks, but their frequent occurrence was inconvenient. There were no other symptoms and no previous medical complaints.

The pulse rate was 60 beats per minute and irregular; blood pressure was $100 / 60 \mathrm{~mm} \mathrm{Hg}$ with no pos- 


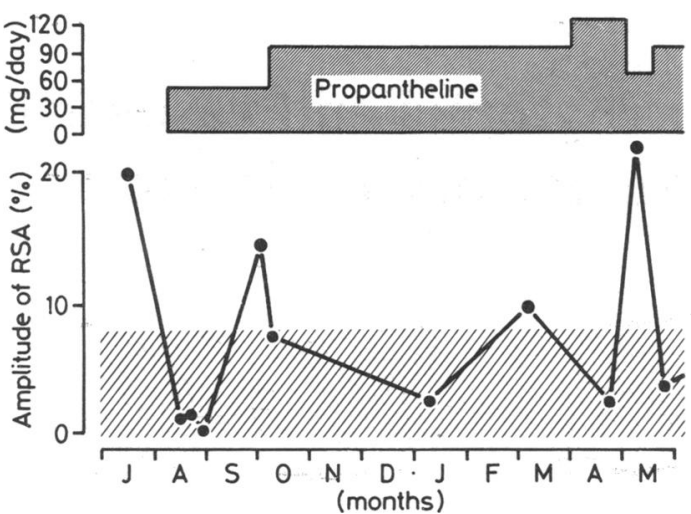

Figure Amplitude of respiratory sinus arrhythmia (RSA) assessed by cosinor analysis in a patient aged 18 with vagotonia. The hatched area represents the $95 \%$ confidence interval for a normal subject of this age.

tural drop. Physical examination was otherwise normal, and carotid sinus massage did not provoke symptoms or cause undue bradycardia. The electrocardiogram was normal but Holter monitoring showed pronounced sinus arrhythmia, intermittent first degree heart block, and one episode of Wenckebach phenomenon.

In July 1985 cosinor analysis of a three minute electrocardiogram recorded during spontaneous respiration showed respiratory sinus arrhythmia with an amplitude of $20.1 \%$, well outside the normal range. At age 18 the predicted normal value is $4.3 \%$, with a $95 \%$ confidence interval of $0.4-8.3 \% .^{7}$

Propantheline $15 \mathrm{mg}$ three times a day rapidly relieved the symptoms and reduced the amplitude of sinus arrhythmia, which in August 1985 was $2 \%$ (figure). In October 1985 vasovagal attacks recurred and the amplitude of respiratory sinus arrhythmia was again excessively high $(15 \%)$. Her symptoms responded to an increase in the dose of propantheline to $30 \mathrm{mg}$ three times a day. The amplitude of sinus arrhythmia immediately fell to $8 \%$, and there was a further fall to $3 \%$ over the next three months. In May 1986 she complained about the number of tablets she was taking and an attempt was made to reduce the dosage. She had attacks of near syncope and the amplitude of sinus arrhythmia increased to $23 \%$. The daily dosage of propantheline was increased again to $90 \mathrm{mg}$ with relief of symptoms and a reduction in the amplitude of sinus arrhythmia to a normal value of $4 \%$. Throughout the 10 month period of treatment with propantheline she had a dry mouth and eye discomfort in bright sunshine, but she preferred these side effects to frequent vasovagal attacks.

\section{Discussion}

Respiratory sinus arrhythmia is mediated reflexly. Because the cardiac vagus nerves are the efferent arm of this reflex sinus arrhythmia is an index of vagal cardiac outflow ${ }^{8}$ and increased vagal tone might be expected to exaggerate sinus arrhythmia. Although there is no mention of sinus arrhythmia in recent papers on vagotonia in which diagnosis was by electrophysiological study, ${ }^{45}$ some older textbooks mention the association of sinus arrhythmia, dizzy spells, and faintness. ${ }^{9}$ Electrophysiological study has a low yield of abnormal findings in patients with unexplained syncope when the electrocardiogram is reported to be normal, ${ }^{10}$ but respiratory sinus arrhythmia is a normal finding at all ages and an abnormally increased amplitude could be easily overlooked.

Electrophysiological studies in 10 patients with vagotonia by Benditt $e t$ al showed that intravenous and oral theophylline had positive chronotropic and dromotropic effects. ${ }^{4}$ An oral preparation was tolerated by eight of their patients and suppressed symptoms in six during a follow up of from five to 24 months. McLaran et al described 12 patients with symptoms similar to our patient. The diagnosis of vagotonia was made by an electrophysiological study in these 12 patients. ${ }^{5}$ They were treated with propantheline, which was beneficial in nine cases; the average period of follow up was 23 months.

In our patient the symptoms and Holter monitor findings were highly suggestive of increased vagal tone and the finding of exaggerated respiratory sinus arrhythmia also supported this diagnosis. The diagnosis was confirmed by the patient's response to propantheline. This relieved symptoms and reduced the amplitude of respiratory sinus arrhythmia to normal.

Measurement of the amplitude of respiratory sinus arrhythmia from a three minute electrocardiogram is not only helpful in making a positive diagnosis of vagotonia, but also in monitoring the efficacy of treatment. It is non-invasive, may be repeated as often as required, and is quicker and more simple than electrophysiological study.

We thank Mrs Joy McKnight for invaluable technical assistance. She is supported by a research grant from Grampian Health Board.

\section{References}

1 Glick G, Yu PN. Hemodynamic changes during spontaneous vasovagal reactions. Am $\mathcal{F}$ Med 1963;34: 42-51.

2 Strasberg B, Lam W, Swiryn S, et al. Symptomatic spontaneous paroxysmal AV nodal block due to local- 
ised hyper-responsiveness of AV node to vagotonic reflexes. Am Heart $J$ 1982;103:795-801.

3 Meytes I, Kaplinsky E, Yahini JH, Hanne-Paparo N, Neufeld HN. Wenckebach AV block: a frequent feature following heavy physical training. Am Heart $J$ 1975;90:426-30.

4 Benditt DG, Benson DW Jr, Kreitt J, et al. Electrophysiological effects of theophylline in young patients with recurrent symptomatic bradyarrhythmias. $\mathrm{Am} \mathrm{J}$ Cardiol 1983;52:1223-9.

5 McLaran CJ, Gersh BJ, Osborn MJ, et al. Increased vagal tone as an isolated finding in patients undergoing electrophysiological testing for recurrent syncope: response to long term anticholinergic agents. $\mathrm{Br}$ Heart $J$ 1986;55:53-7.
6 Halberg F, Johnson EA, Nelson W, Runge W, Sothern R. Autorhythmometry-procedures for physiologic self-measurements and their analysis. Physiology Teacher 1972;1(4):1-11.

7 Pai GR, Reid SR, Rawles JM. A method of quantifying sinus arrhythmia: parallel effect of respiration on P-P and $P-R$ intervals. Unpublished.

8 Eckberg DL. Human sinus arrhythmia as an index of vagal cardiac outflow. J Appl Physiol 1983;54:961-6.

9 Bellet S. Clinical disorders of the heart beat. Philadelphia: Lea and Febiger, 1971:142.

10 Gulamhusein S, Naccarelli GV, Ko PT, et al. Value and limitations of clinical electrophysiological study in assessment of patients with unexplained syncope. Am J Med 1982;73:700-5. 